\title{
THE OXIDE-FORMING ROLE OF WATER IN ALUMINUM ELECTROLYTIC CAPACITORS
}

\author{
WALTER J. BERNARD and STEVEN M. FLORIO \\ Sprague Electric Company, North Adams, MA 01247
}

(Received January 11, 1983; in final form March 19, 1983)

Key Words: aluminum; anodization; organic electrolyte; electrolytic capacitors; water content.

\begin{abstract}
The effect of the water content of several electrolytic solutions on their ability to form dielectric oxide films on aluminum was examined. Anhydrous electrolytes were found to be incapable of forming such films, but the addition of small amounts of water made it possible for these solutions to perform as normal oxide-film formers. The anodizing behavior of an anhydrous electrolyte composed of methyl cellosolve and ammonium picrate was investigated in detail in both experimental aluminum anodizations and in finished capacitors, in an attempt to correlate the behavior of the electrolyte as an anodizer of bare foil with the aging and life test characteristics of capacitors containing that electrolyte. The results tend to support the conclusion that water is essential to the proper performance of electrolytic capacitors.
\end{abstract}

\section{INTRODUCTION}

It is generally believed that water is a necessary component in electrolytes used for the formation of oxide films on aluminum and other valve metals. ${ }^{1}$ Duffek, et al. ${ }^{2}$ oxidized silicon in glycol solutions and found that traces of water $(0.1-1 \%)$ were necessary for the best oxide characteristics, and Croset et al. ${ }^{3}$ using ${ }^{18} \mathrm{O}$ in the anodization of silicon and tantalum reported that about $80 \%$ of the oxygen in the oxide arises from water; however, in the latter study no anhydrous solutions were studied. It is, therefore, probably essential that water be present in the operating electrolyte of an aluminum electrolytic capacitor where it functions as the source of oxygen for the formation of oxide during the anodization of bare foil edges and oxide defects after capacitor construction. The presence of water in the electrolyte may arise from several sources: direct addition during electrolyte preparation, chemical reactions within the electrolyte which form water, extraction from the porous cellulosic spacer which separates anode and cathode foils, or adsorption from the atmosphere during makeup and processing. In the past, the presence of fairly large amounts of water in operating electrolytes had limited their application in capacitors to temperatures under $100^{\circ} \mathrm{C}$ because of containment problems, and because of increased reactivity with other capacitor materials at temperatures greater than $100^{\circ} \mathrm{C}$.

The recent trend in aluminum electrolytic capacitor design has been toward higher operating temperature capability with increased device stability. In order to produce capacitors which are stable at temperatures up to $150^{\circ} \mathrm{C}$, it has, in many cases, been necessary to minimize the concentration of water present in the operating electrolyte. The intent of this work is to show that the presence of water is critical to the formation of a normal dielectric oxide on aluminum, and to show the effect of an electrolyte of known water content on long term, high temperature capacitor performance.

In principle it should be possible to determine whether water or some other electrolyte constituent plays the essential part in the anodization process by simply comparing the anodizing behavior of anhydrous electrolytes with conventional aqueous solutions. This is 
not, however, as easily accomplished as it may appear. The most interesting solutes those with the best anodizing characteristics - are borates and phosphates. Both solutes may be subject to either esterification or condensation in some nonaqueous solvents, giving rise to uncertain amounts of water, and the results obtained by the anodic oxidation of aluminum in such solutions are necessarily obscured to some extent by these reactions. ${ }^{4}$ In those cases in which the solute and solvent cannot react to form water the solutions can presumably be made "anhydrous" in the conventional sense, but the problem in this instance is rendered difficult by consideration of the extremely minute amounts of water required for the electrochemical reaction needed to bring about the formation of anodic oxide films. It may be calculated, for example, that one gram of solution need contain only $0.002 \%$ water in order to form an oxide film $1200 \AA$ thick (about 100 volts) on one square centimeter of aluminum. It is not intended to imply here that such a low concentration of water could be used with a very high electrochemical efficiency, but the calculation nevertheless points out that extreme care should be taken to exclude water, and even then the view that the solution may be considered to be strictly "anhydrous" may still be questioned.

\section{EXPERIMENTAL}

\section{A. Materials}

Several different electrolyte systems were included in this investigation, but the capacitor study was carried out only with ammonium picrate dissolved in methyl cellosolve.Preparation of this electrolyte, therefore, received particular care (described below), and the absolute water content was determined for both the anhydrous formulation and one to which a measured amount of water was added.

All formulations were prepared from electronic grade, reagent grade, or other highest grade chemicals available. The picric acid which was utilized in the preparation of ammonium picrate originally contained approximately $10 \%$ water for the purpose of stabilization. Aluminum specimens were cut from a roll of Alcoa $7.6 \times 10^{-3} \mathrm{~cm}, 99.99 \%$ stock, and were electropolished ${ }^{5}$ prior to anodization. All other chemicals were used as received.

The conventional axial-style capacitor sections which were utilized in evaluating the electrolytes consisted of concentrically wound layers of $6.1 \times 10^{-3} \mathrm{~cm}$ thick Manila paper separating the anode and cathode. The aluminum anode foil was electrochemically etched by a commercial process to increase the active surface area, and electrochemically oxidized in dilute ammonium phosphate solution at constant applied current to a barrier voltage of $80 \mathrm{~V}$. The cathode foil was also etched and was similarly anodized to a barrier voltage of $2 \mathrm{~V}$. The housing for the capacitor was an aluminum can. The cover assembly consisted of Teflon and butyl rubber, with an aluminum insert at which connection to the anode termination was possible.

\section{B. Apparatus}

A Labconco Glove Box, which was dried with $\mathrm{P}_{2} \mathrm{O}_{5}$ and continually flushed with dry nitrogen, was utilized for the preparation of Electrolyte A-1, the anodization of aluminum in A-1, and capacitor impregnation and partial assembly. The Pyrex cell which was used for anodization was water-jacketed for temperature control; a Teflon cell top accomodated platinum counter electrodes and a thermometer. Constant current for anodization was provided by a Northeast Scientific Company Model R1-234 Power Supply.

Karl-Fisher titrations for $\mathrm{H}_{2} \mathrm{O}$ were performed using a Beckman KFA Aquameter. The capacitance and dissipation factor of anodized foil samples and of finished capacitors 
were measured in the series mode by a General Radio 1657 RLC Digibridge.

Capacitor aging and life testing were carried out in Precision circulating air ovens, using Regatron Model 209B regulated constant voltage power supplies. Leakage current measurements were made using a Voltex Model 82-160 regulated constant voltage power supply with a current-limiting resistor.

\section{Procedures}

Electrolyte preparation. Dry ammonium picrate was prepared by dissolving $34.5 \mathrm{~g}(\sim 0.14$ mol) of picric acid (10\% water by weight) in a minimum amount of ethanol at $65^{\circ} \mathrm{C}$. Upon cooling to room temperature, this solution was treated with $12.0 \mathrm{~g}$ concentrated ammonium hydroxide $(28-30 \%, \sim 0.2 \mathrm{~mol})$. This solution was cooled to $0^{\circ} \mathrm{C}$. The yellow crystalline product was collected by vacuum filtration under a brisk flow of dry nitrogen. The crystals were washed repeatedly with cold anhydrous ethanol to remove traces of water, followed by multiple washings with anhydrous ether. The product was transferred to a desiccator, and stored under nitrogen until use. Methyl cellosolve was dried by distillation from calcium hydride, and stored under nitrogen until use.

The preparation of picrate electrolytes was conducted in a $\mathrm{P}_{2} \mathrm{O}_{5}$-dried glove box under dry nitrogen flow. The anhydrous electrolyte, designated A-1, was prepared by dissolution of $20.0 \mathrm{~g}$ of anhydrous ammonium picrate in $100 \mathrm{~g}$ of dry methyl cellosolve. The resistivity of this electrolyte at $25^{\circ} \mathrm{C}$ was $177 \Omega-\mathrm{cm}$. A second electrolyte, designated A-2, was prepared by adding approximately $2.8 \%$ water to A-1 by weight. The resistivity of this electrolyte was $150 \Omega-\mathrm{cm}$. Both electrolytes were analyzed for $\mathrm{H}_{2} \mathrm{O}$ content by KarlFisher titration. The samples were withdrawn from septum-stoppered containers by syringe, and injected into the Karl-Fisher apparatus to minimize exposure of the electrolytes to the air.

For all other electrolytes special precautions were taken to maintain dry conditions: solutes were vacuum-dried and solvents were dried by appropriate means and redistilled, in some cases directly into a cell containing the anhydrous solute.

\section{Aluminum Anodization}

Anodization of $17.7 \mathrm{~cm}^{2}$ electropolished aluminum specimens was attempted in A-1 and A-2 electrolytes. Oxide formation in A-1 was carried out under nitrogen at $25^{\circ} \mathrm{C}$ and $1.0 \mathrm{~mA} / \mathrm{cm}^{2}$ in the glove box, until maximum voltage was achieved. Formations in A-2 were carried out at both $25^{\circ} \mathrm{C}$ and $85^{\circ} \mathrm{C}$ in the atmosphere at $1.0 \mathrm{~mA} / \mathrm{cm}^{2}$, until maximum voltage was achieved. Additional formations in a standard ethylene glycol-ammonium pentaborate electrolyte were carried out at $25^{\circ} \mathrm{C}$ and $85^{\circ} \mathrm{C}$ in the atmosphere at $1.0 \mathrm{~mA} / \mathrm{cm}^{2}$ for the purpose of comparison. Where possible, the capacitance of samples anodized to $50 \mathrm{~V}$ were measured in aqueous ammonium borate $\left(\rho=190 \Omega-\mathrm{cm}\right.$ at $\left.25^{\circ} \mathrm{C}\right)$ in a Pyrex cell with platinized platinum counterelectrodes suspended from a Teflon head.

\section{E. Capacitor Construction}

Four groups of capacitors were constructed: A-1 electrolyte in vacuum-dried capacitor sections (Group I); A-2 in vacuum dried capacitor sections (Group II); A-1 in normal capacitor sections (Group III); and A-2 in normal capacitor sections (Group IV). For Groups I and II, the sections were vacuum-dried at $90-100^{\circ} \mathrm{C}$ for two hours, and the weight changes were recorded. Tabs from the cathode foil to the can and from the anode foil to the cover assembly had previously been welded in place for termination purposes. Immediately after drying, these sections were transferred from a $\mathrm{P}_{2} \mathrm{O}_{5}$-dried desiccator to the glove box for electrolyte impregnation. 
Impregnation of twelve-piece lots from Groups I, II, III and IV were carried out in the glove box by immersing the appropriate sections in A-1 or A-2 electrolyte at $25^{\circ} \mathrm{C}$, at atmospheric pressure, for one hour. The excess electrolyte was drained off, and the cover assemblies were loosely fitted into place prior to sealing. All capacitors were then removed from the glove box and quickly sealed. This step allowed for possible absorption of water from the air by the hydroscopic electrolyte, even though the exposure was very brief.

\section{F. Capacitor Aging}

Each capacitor was aged at $85^{\circ} \mathrm{C}$ with $60 \mathrm{~V}$ applied across the capacitor in series with a $35 \mathrm{~K} \Omega-10 \mathrm{~W}$ resistor for 18 hours. Post-resistor voltages for each capacitor were recorded at various intervals.

\section{G. Capacitor Life Testing}

The capacitance, dissipation factor, and D.C. leakage current of each capacitor was measured. Each capacitor was then life tested by applying $50 \mathrm{VDC}$ to the capacitor in a circulating air oven at $85^{\circ} \mathrm{C}$ for a total of 1000 hours; at 250 hour intervals, the capacitance, \% D.F., and D.C. leakage currents were recorded. At the conclusion of 1000 hours, electrolyte was collected from each group of capacitor sections in the glove box, and was analyzed by Karl-Fisher titration for $\mathrm{H}_{2} \mathrm{O}$ content.

\section{RESULTS AND DISCUSSION}

\section{A. Aluminum Anodization Experiments}

All solutes and solvents used in these experiments have oxygen in their molecular composition. In each electrolyte system, therefore, the conditions under which an oxide film forms provides an unambiguous determination of the source of oxygen.

\section{Ethanolammonium trifluoroacetate in ethylene glycol.}

An electrolyte consisting of $50 \%$ by weight of solute has found some commercial application $^{6}$ and it was known that water had an effect on its behavior. When an anhydrous solution was prepared it was found that oxide film formation did not take place; the maximum voltage drop in the cell remained below 20 volts at constant current. Gaseous and solid electrolysis products were generated at the anode but no attempt was made to identify them. The addition of small amounts of water resulted in an increase in the anode voltage, and at a concentration of $0.8 \% \mathrm{H}_{2} \mathrm{O}$, an oxide formation of about 200 volts was achieved.

2. Tributylammonium picrate in tributyl phosphate.

A solution which was prepared under anhydrous conditions in a vacuum system, containing $17.0 \%$ salt by weight, gave an apparent formation voltage of 8 volts on aluminum. The only visible anodic product was a dark oily substance. The addition of $1 \%$ by weight of water to a fresh solution resulted in a clean formation to 190 volts. No intermediate water concentration was studied.

3. Triethylammonium tartrate in ethanol.

This solution was of special interest because of the good formation characteristics of 
TABLE I

Effect of water on anodization properties

\begin{tabular}{llrll}
\hline Electrolyte & $\begin{array}{l}\text { Temp. } \\
\left({ }^{\circ} \mathrm{C}\right)\end{array}$ & $\mathrm{V}_{\max }$ & $\begin{array}{l}\text { Rate, 0-50 V } \\
(\mathrm{V} / \mathrm{min} .)\end{array}$ & $\begin{array}{l}\text { Capacitance, 50 V } \\
\left(\mu \mathrm{F} / \mathrm{cm}^{2}\right)\end{array}$ \\
\hline A-1 (Anhydrous) & 25 & $<3$ & - & - \\
A-2 $\left(2.6 \% \mathrm{H}_{2} \mathrm{O}\right)$ & 25 & 100 & 27.0 & 0.132 \\
Glycol-Borate & 25 & $>300$ & 28.7 & 0.132 \\
A-2 & 85 & 80 & 22.2 & 0.112 \\
Glycol-Borate & 85 & $>300$ & 25.0 & 0.116 \\
\hline
\end{tabular}

tartrates in aqueous solution, and this electrolyte afforded us an opportunity to study the behavior of the tartrate alone. In the anhydrous solution containing $2.5 \%$ solute a formation voltage of 10 volts was attained, whereas the addition of $1 \%$ water permitted a formation of 250 volts.

\section{Ethanolammonium citrate in ethylene glycol.}

Aqueous citrates are also fairly good anodizing electrolytes, and it was desirable to include an appropriate representative of this class in these experiments. No oxide formation was observed in the anhydrous $2 \%$ salt solution, while the addition of $3 \%$ water gave a formation in the region of 50 volts. Anodizations were quite poor over a large range of water concentrations, but there was no doubt that the presence of water was essential for even poor quality films to be formed.

\section{Ammonium picrate in methyl cellosolve.}

The precautions taken to produce an anhydrous electrolyte, A-1, were effective, as shown by the Karl-Fisher titrations for $\mathrm{H}_{2} \mathrm{O}$. Electrolyte A-1 was found to contain $0.06 \%$ $\mathrm{H}_{2} \mathrm{O}$, and electrolyte A-2, to which an estimated $2.8 \% \mathrm{H}_{2} \mathrm{O}$ has been added, was shown to contain $2.61 \% \mathrm{H}_{2} \mathrm{O}$. Anodization of aluminum foil was carried out in $\mathrm{A}-1$ in the glove box under dry nitrogen at $25^{\circ} \mathrm{C}$; no comparable experiments were run at $85^{\circ} \mathrm{C}$ because of glove box limitations. Anodizations were performed in both A-2 and a conventional electrolyte, consisting of $17 \%$ ammonium pentaborate in ethylene glycol ${ }^{\dagger}$, at $25^{\circ}$ and $85^{\circ} \mathrm{C}$ in the ordinary laboratory atmosphere.

Electrolyte A-1 was unable to form an oxide film on aluminum at $25^{\circ} \mathrm{C}$. The initial voltage drop across the formation cell at $18.0 \mathrm{~mA}$ was 3.0 volts, and remained at that level for several minutes. The experiment was then discontinued, as the anode became discolored by a dark decomposition product generated during charge passage.

Anodization in A-2 electrolyte contrasted sharply with that in A-1; it proceeded to 100 volts at $25^{\circ} \mathrm{C}$, and to 80 volts at $85^{\circ} \mathrm{C}$. In this electrolyte the anodization rates and capacitance values of aluminum oxidized to 50 volts were essentially the same as the values found in the glycol-borate electrolyte. Comparison of the data in Table I indicates that the film formed in A-2 is the conventional barrier oxide, since the oxidation of aluminum in glycol-borate electrolytes has been shown to be an essentially $100 \%$ efficient process for the formation of stoichiometric $\mathrm{Al}_{2} \mathrm{O}_{3}$.

The fact that the addition of $2.61 \% \mathrm{H}_{2} \mathrm{O}$ to A-1 electrolyte brought about normal

\footnotetext{
$\dagger^{\top}$ This electrolyte has been shown to contain $\sim 7 \%$ water by weight as a result of esterification between glycol and boric acid.
} 
oxide formation supports the idea that water is an essential component in an operating electrolyte. The actual amount of water which is necessary may be questioned. It may be calculated that for the formation of a 100 volt film of stoichiometric $\mathrm{Al}_{2} \mathrm{O}_{3}$ on $17.7 \mathrm{~cm}^{2}$ of Al, only $400 \mu \mathrm{g}$ in $100 \mathrm{~g}$ of operating electrolyte need be $\mathrm{H}_{2} \mathrm{O}$, if in fact the oxygen of $\mathrm{H}_{2} \mathrm{O}$ is the sole source of oxide oxygen. Even in A-1 electrolyte, the amount of water far exceeds this amount. It appears, then, that while enough water may be present for the oxide to form, its concentration is too low for it to participate in the required electrochemical reaction to any appreciable degree. In the presence of less than some critical amount of water, the rate of stoichiometric oxide formation must be much slower than the usual secondary anodic processes such as solute decomposition, anomalous film formation, aluminum dissolution, or gas production.

\section{B. Capacitor Testing}

The capacitor testing was designed to determine whether the same dependence on water would hold in a capacitor structure when the extent of actual anodization required under these conditions was far below that required for forming oxide on a large area of bare foil, as it was in the case of electropolished aluminum foil. The unformed anode tab, the anode cover insert, and the cut edges of the anode foil present the principal demand on the electrolyte during capacitor aging. The amount of oxide formed in the capacitor is trivial when compared to the actual amount of water available in electrolytes A-1 and A-2. In order to keep the amount of water down to the low levels of A-1 or A-2, it was necessary to take special precautions during the capacitor manufacture.

It was shown that the electrolyte could be kept sufficiently free of water during electrolyte makeup. The rolled capacitor section, however, is known to contain an appreciable amount of water, primarily in the porous cellulosic spacer. This water could conceivably be absorbed into the electrolyte after the capacitor is assembled. In order to remove the uncertainty of this variable, half of the capacitors which were impregnated with A-1, and half of the capacitors which were impregnated with A-2, were vacuum dried before impregnation. This vaccum drying at $100^{\circ} \mathrm{C}$ for one hour was shown to remove an average of $0.012 \mathrm{~g}$ of $\mathrm{H}_{2} \mathrm{O}$ from capacitor sections that had been stored at $25^{\circ} \mathrm{C}$ and $100 \%$ relative humidity prior to drying. The impregnated capacitors contained an average of $1.210 \mathrm{~g}$ of electrolyte. If all of this water were absorbed into the electrolyte, the additional water would constitute about $1 \%$ of the electrolyte. It was clearly reasonable, therefore, to examine experimentally the possible effects of this spacer-derived $\mathrm{H}_{2} \mathrm{O}$ on capacitor performance.

The results of electrical aging of each of the four groups of capacitors (Table II) showed a clear difference between Group I, where A-1 and predried sections were used,

TABLE II

Median aging current at $85^{\circ} \mathrm{C}$

\begin{tabular}{llcc}
\hline Group & Electrolyte/ & Time & Median \\
& Cap. Section & $(\mathrm{Hrs})$ & DCL $(\mu \mathrm{A})$ \\
\hline I & A-1/Pre-dried sections & 1 & 242.9 \\
& & 18 & 2.3 \\
II & A-2/Pre-dried sections & 1 & 71.4 \\
& & 18 & 2.6 \\
III & A-1/Standard sections & 1 & 57.1 \\
& & 18 & 2.3 \\
IV & A-2/Standard sections & 1 & 54.3 \\
& & 18 & 2.9 \\
\hline
\end{tabular}




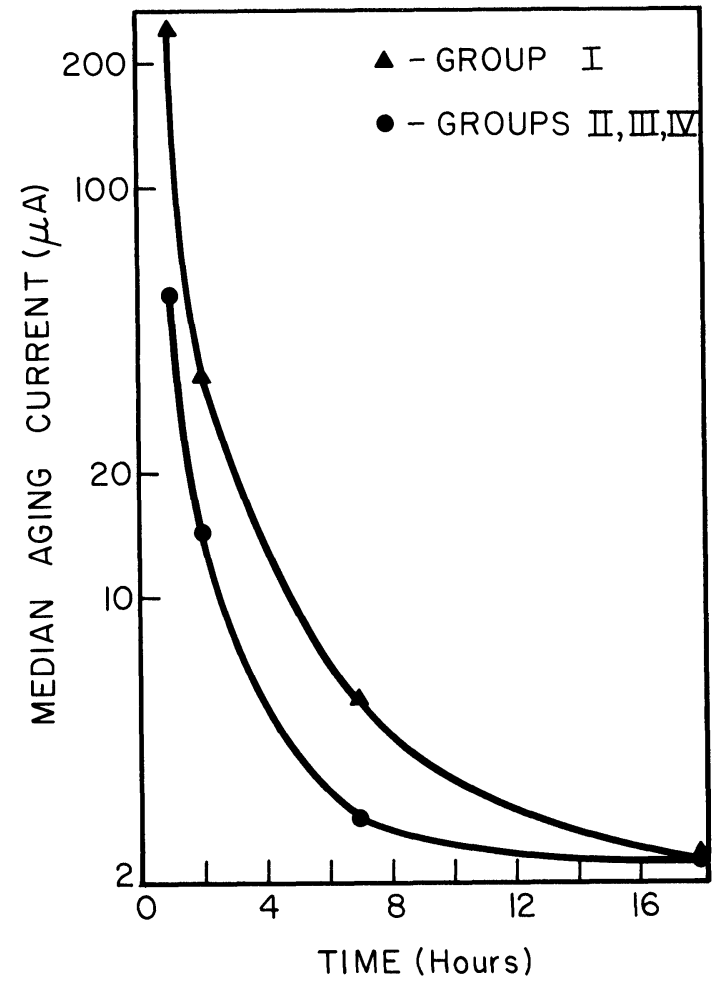

FIGURE 1 Aging behavior of experimental capacitors containing ammonium picrate - methyl cellosolve electrolytes.

and the other three groups. Figure 1 , a plot of median $85^{\circ} \mathrm{C}$ aging current versus time, shows that the lower water content of Group I capacitors is reflected in higher initial aging currents. Toward the end of the eighteen hour aging all capacitors approached the same minimum aging current of 2.0 to $2.9 \mathrm{~mA}$. During capacitor construction and the 18 hour aging period, it seems likely that either the electrolyte in Group I acquired enough additional water to function as a progressively better operating electrolyte, or that oxide formation proceeded despite the lower water concentration in the electrolyte.

Aged capacitors from Groups I-IV were then subjected to a 1000 hour life test at $85^{\circ} \mathrm{C}$, with $50 \mathrm{~V}$ applied. After $0,250,500$, and 1000 hours of testing, the capacitors were measured for capacitance, \% D.F., and D.C. leakage current. The results at the beginning and end of testing are contained in Table III. It is important to note that the initial D.C. leakage current measured at $25^{\circ} \mathrm{C}$ in Group I capacitors were, on the average, higher than those measured in Groups II-IV, despite the fact that the final $85^{\circ} \mathrm{C}$ currents were similar. This behavior emphasized the differences in the properties of the oxides formed at $25^{\circ} \mathrm{C}$ and $85^{\circ} \mathrm{C}$.

The properties of the different capacitor groups during the course of the life test were essentially the same in terms of capacitance and leakage current. The somewhat higher $\%$ D.F. values of Group I are probably a reflection of the slightly higher resistivity of A-1 and the more difficult wetting of the aluminum electrodes and the Manila spacer with less water present.

Determination of the $\mathrm{H}_{2} \mathrm{O}$ content of electrolyte samples secured from Groups I-IV at the conclusion of life testing gave results contained in Table IV. From these data, it may 
TABLE III

Life test at $85^{\circ} \mathrm{C}$

\begin{tabular}{lrlll}
\hline & $\begin{array}{r}\text { Time } \\
\text { Group }\end{array}$ & $\begin{array}{l}\text { Capacitance } \\
\text { (Hrs) }\end{array}$ & $\begin{array}{l}\% \mathrm{D} . \mathrm{F} . \\
\text { @ } 25^{\circ} \mathrm{C}\end{array}$ & $\begin{array}{l}\text { Median D. C. } \\
\text { Leakage Current } \\
@ 25^{\circ} \mathrm{C}(\mu \mathrm{F})\end{array}$ \\
\hline I & 0 & 123.2 & 3.43 & 1.16 \\
II & 1000 & 122.1 & 3.32 & 0.33 \\
& 0 & 123.6 & 3.11 & 0.57 \\
III & 1000 & 122.4 & 2.67 & 0.34 \\
& 0 & 122.7 & 3.39 & 0.78 \\
IV & 1000 & 122.5 & 2.52 & 0.25 \\
& 0 & 122.3 & 3.20 & 0.63 \\
& 1000 & 122.1 & 2.51 & 0.42 \\
\hline
\end{tabular}

be seen that the electrolyte from all groups absorbed water during capacitor sealing and testing. As might be expected, Groups I and III, which contained A-1, absorbed water more rapidly $(+1.10$ and $+1.30 \%$, respectively) than Groups II and IV which contained A-2 (+0.35 and $+0.75 \%$, respectively). In the capacitors in which the sections had not been pre-dried, some water was also absorbed into the electrolyte from the section. The amount of water absorbed from the sections in Group III was calculated to be about $0.3 \%$, and in Group IV about $0.4 \%$. It is of interest to note that the capacitor section did not contribute all of its water to the operating electrolyte. In a specific capacitor design, the actual amount of water which is contributed by the section would be expected to vary with the weight ratio of paper to electrolyte, the chemical composition of the electrolyte, and the type and history of the paper and foil.

\section{CONCLUSION}

Water has been shown to be an essential, and usually inescapable, component of the working electrolyte of aluminum electrolytic capacitors. In the design of a particular capacitor, it would be reasonable to take precautions to assure that the water content of the electrolyte exceeds some desired minimum, taking into account the possibilities of adsorption of water from the atmosphere and extraction from the other structural elements of the capacitor section.

\section{ACKNOWLEDGEMENTS}

The authors wish to thank Mr. S. Szpak and Mr. R. MacDonald for their assistance during the course of this work, and Dr. M. Finkelstein for the preparation of dry methyl cellosolve.

TABLE IV

Water content of electrolyte after life test

\begin{tabular}{lc}
\hline Group & \% Water \\
\hline I & 1.16 \\
II & 2.96 \\
III & 1.46 \\
IV & 3.39 \\
\hline
\end{tabular}




\section{REFERENCES}

1. L. Young, Anodic Oxide Films, Academic Press, New York (1961), p. 113.

2. E.F. Duffek, E.A. Benjamini, and C.A. Mylroie, Electrochem. Technol., 3, 75 (1965).

3. M. Croset, et al., J. Electrochem. Soc., 118, 717 (1971).

4. S. Tajima, N. Baba, and T. Mori, Electrochim. Acta, 9, 1509 (1964).

5. P.A. Jaquet, Met. Revs., 1, 157 (1956).

6. W.J. Bernard. M. Markarian, and S.D. Ross, U.S. Patent 2, 932, 153 (1960).

7. W.J. Bernard and J.W. Cook, J. Electrochem. Soc., 106, 643 (1959). 

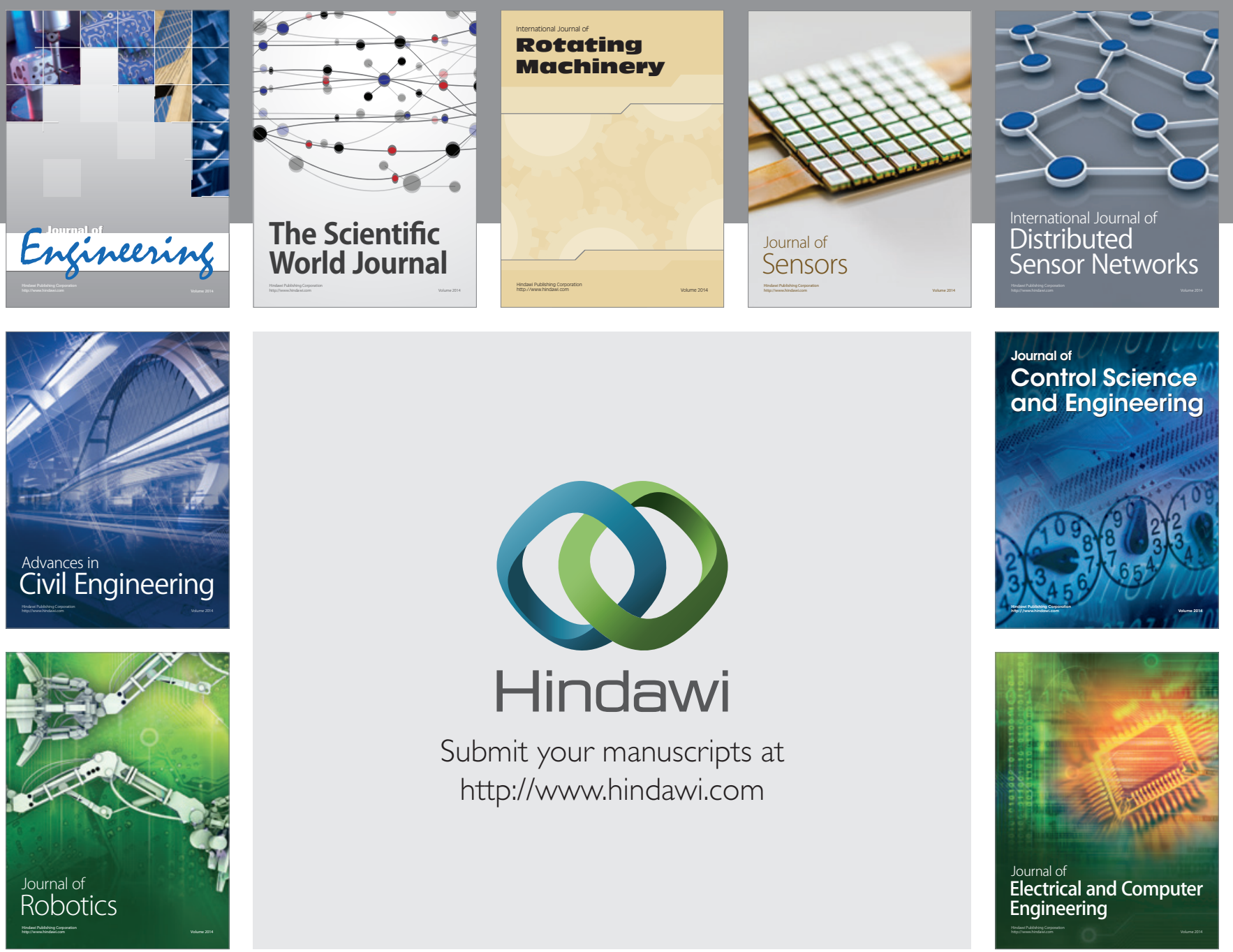

Submit your manuscripts at

http://www.hindawi.com
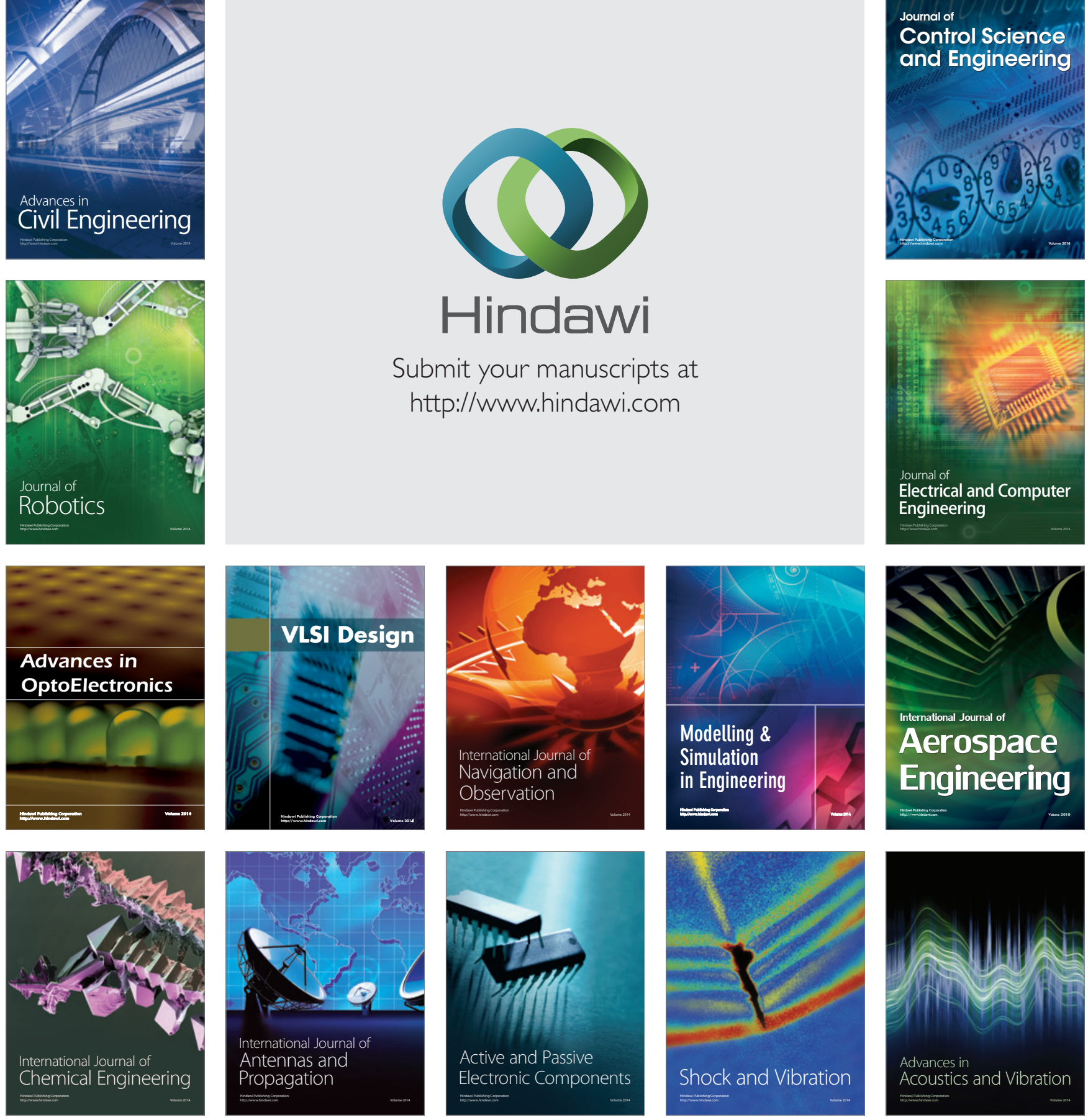